\title{
Hourglass brain
}

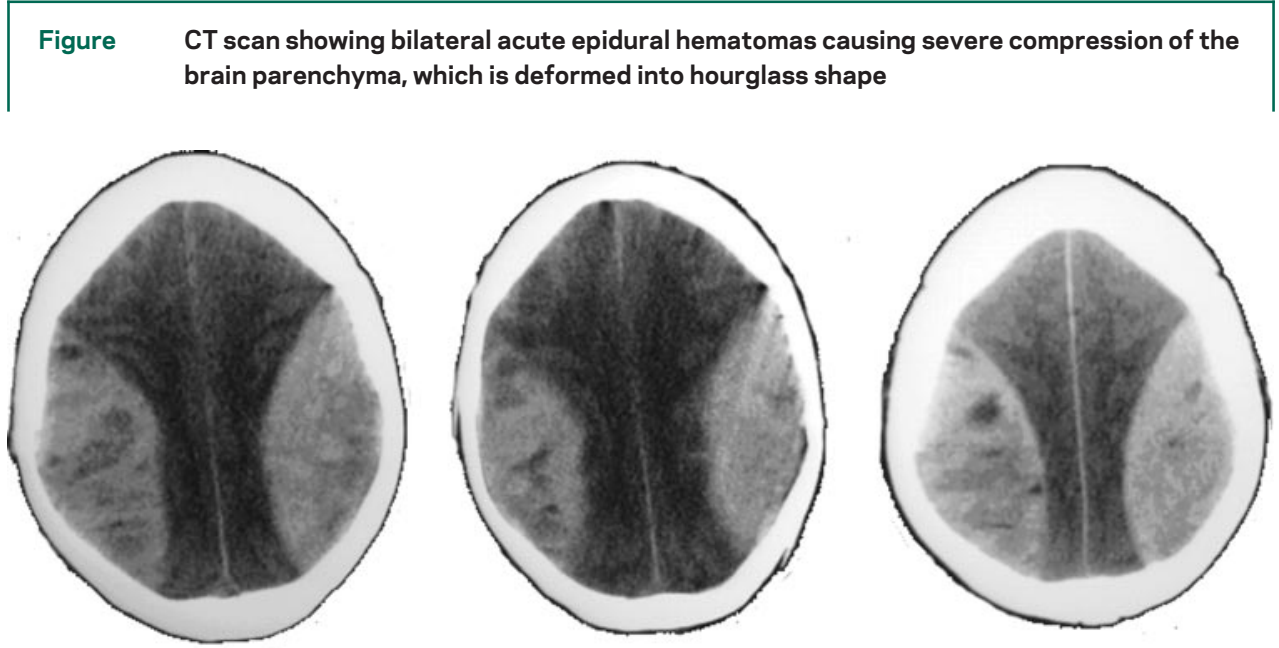

A 50-year-old man was admitted with repeated alcoholic withdrawal seizures and head trauma, followed by coma. CT scan showed large bilateral acute epidural hematomas (figure). Bilateral craniotomy and drainage were performed. Afterward, the patient regained consciousness but remained mute, with spastic tetraparesis and refractory epilepsy.

Bilateral epidural hematomas are exceedingly rare, accounting for $2.58 \%$ of all epidural hematomas; they cause high mortality and morbidity; and they usually occur after severe head injury, e.g., car accidents. ${ }^{1,2}$ In this case, chronic alcoholism may have resulted in a mild coagulation disorder, and seizure-induced repeated head trauma provoked bilateral synchronous epidural bleeding.

\section{R.M. Guerreiro, MD, P. Fontoura, MD, PhD, Setúbal, Portugal}

Disclosure: The authors report no disclosures.

Address correspondence and reprint requests to Dr. R.M. Guerreiro, Department of Neurology, Centro Hospitalar de Setúbal, Rua Camilo Castelo Branco, 2900 Setúbal, Portugal; rpguerreiro@gmail.com

1. Gorgulu A, Çobanuglu S, Armagan S, Karabagh H, Tevruz M. Bilateral epidural hematoma. Neurosurg Rev 2000;23:30-33.

2. Gelabert-Gonzalez M, Iglésias M, Serranito R, Fernandez J, Garcia A, Martinez R. Hematomas epidurales bilaterales simultáneos. Neurocirugia 2005;16:256-260. 


\title{
Neurology
}

\author{
Hourglass brain \\ R. M. Guerreiro and P. Fontoura \\ Neurology 2008;71;149 \\ DOI 10.1212/01.wnl.0000316809.62935.79
}

This information is current as of July 7, 2008

\section{Updated Information \& Services}

\section{References}

\section{Subspecialty Collections}

\section{Permissions \& Licensing}

\section{Reprints}

including high resolution figures, can be found at: http://n.neurology.org/content/71/2/149.full

This article cites 2 articles, 0 of which you can access for free at: http://n.neurology.org/content/71/2/149.full\#ref-list-1

This article, along with others on similar topics, appears in the following collection(s):

\section{Alcohol}

http://n.neurology.org/cgi/collection/alcohol

Brain trauma

http://n.neurology.org/cgi/collection/brain_trauma

Coma

http://n.neurology.org/cgi/collection/coma

\section{CT}

http://n.neurology.org/cgi/collection/ct

Nonepileptic seizures

http://n.neurology.org/cgi/collection/nonepileptic_seizures

Information about reproducing this article in parts (figures,tables) or in its entirety can be found online at:

http://www.neurology.org/about/about_the_journal\#permissions

Information about ordering reprints can be found online: http://n.neurology.org/subscribers/advertise

Neurology ${ }^{\circledR}$ is the official journal of the American Academy of Neurology. Published continuously since 1951, it is now a weekly with 48 issues per year. Copyright . All rights reserved. Print ISSN: 0028-3878. Online ISSN: 1526-632X.



